\title{
On the Efficiency of Destination and Origin Commodity Taxation in the Presence of Consumption Generated Cross-Border Pollution
}

\author{
Fabio Antoniou \\ Panos Hatzipanayotou \\ Michael S. Michael \\ Nikos Tsakiris
}

CESIFO WORKING PAPER NO. 6221

CATEGORY 1: PUBLIC FINANCE

NOVEMBER 2016

An electronic version of the paper may be downloaded

- from the SSRN website:

- from the RePEc website:

www.SSRN.com

www.RePEc.org

- from the CESifo website:

www.CESifo-group.org/wp 


\title{
On the Efficiency of Destination and Origin Commodity Taxation in the Presence of Consumption Generated Cross-Border Pollution
}

\begin{abstract}
We combine consumption generated cross-border pollution and public pollution abatement in a theoretical framework to examine the efficiency of the destination and origin principles of commodity taxation. The key result of our study is that with public pollution abatement, the non-cooperative equilibrium origin-based consumption taxes are set efficiently. This result holds not only in the context of symmetric countries, but under certain conditions carry over also to asymmetric countries. The non-cooperative equilibrium destination-based consumption taxes are inefficient. In the absence of public pollution abatement, the Nash equilibrium commodity taxes under either taxation principle are inefficient.
\end{abstract}

JEL-Codes: H210, H230, H870.

Keywords: commodity taxation, destination principle, origin principle, cross-border pollution.

\author{
Fabio Antoniou \\ Department of Economics \\ University of Ioannina \\ P.O. Box 1186 \\ Greece - 45110 Ioannina \\ fantoniou@cc.uoi.gr \\ Michael S. Michael \\ Department of Economics \\ University of Cyprus \\ P.O. Box 20537 \\ Cyprus - Nicosia, CY 1678 \\ m.s.michael@ucy.ac.cy
}

\author{
Panos Hatzipanayotou* \\ Department of International and \\ European Economic Studies / Athens \\ University of Economics and Business \\ 76, Patission str. \\ Greece-Athens 10434 \\ hatzip@aueb.gr
}
Nikos Tsakiris
Department of Economics
University of Ioannina
P.O. Box 1186
Greece - 45110 Ioannina
ntsak@cc.uoi.gr

*corresponding author

November 22, 2016

We thank the participants of the Asian Meeting of the Econometric Society, AMES 2016, the 22nd Annual Conference of the European Association of Environmental and Resource Economists, EAERE 2016, and those of the Annual Meeting of the Association of Southern European Economic Theorists, ASSET 2016. Any remaining errors solely burden the authors. 


\section{Introduction}

\subsection{The issue at hand}

At the Paris climate conference (COP21) in December 2015, 195 countries adopted the first-ever universal, legally binding global climate deal. The Paris Agreement is an agreement within the United Nations Framework Convention on Climate Change (UNFCCC) dealing with greenhouse gases emissions mitigation, adaptation and finance starting in the year 2020 1

A significant part of greenhouse emissions, e.g., $\mathrm{CO}_{2}$ emissions, are attributed to consumption or residential activity. Hu and McKitrick (2015) report that "... According to the US Environmental Protection Agency (EPA 2012), nearly one half of the emissions of smog-forming volatile organic compounds (VOCs), more than half of the nitrogen oxides (NOx) emissions, and about half of the toxic air pollutant emissions in US are generated from motor vehicles. ... For OECD countries, up to $90 \%$ of the total carbon monoxide $\left(\mathrm{CO}_{2}\right)$ is from the source "road" (OECD Statistics 2012).... The emissions related to consumption of energy in US are accountable for about $71 \%$ of US carbon dioxide emissions...". Also, in 2014, EPA reports that in the US, about 40 percent of greenhouse gases are attributed to residential activity ${ }^{2}$

When pollution is generated from consumption, hardly ever control policies such as the ones implemented to combat production generated pollution, e.g., emissions taxes, emissions permits, source or sector specific emissions quotas, can be applied to contain consumption emissions. More likely than not, consumption taxes, such, excise and sales taxes, and general goods and services taxes (GSTs) are policy instruments which can be applied in order to control consumption generated environmental externalities. Indeed, recently many governments have used general consumption taxes or excise taxes on specific goods and services either to discourage "harmful" behaviors or to encourage "responsible" ones towards the environment in order to improve welfare. Such have been taxes on energy-consuming products, mineral oils and transport fuels, and taxes on products which produce environmentally harmful emissions, e.g., vehicles $3^{3}$

These revenue yielding tax policies gain an advantage relative to other environmental policies

\footnotetext{
${ }^{1}$ As of October 2016, 191 UNFCCC members have signed the treaty, 81 of which have ratified it. After the European Union ratified the agreement in October 2016, there were enough countries that had ratified the agreement that produce enough of the world's greenhouse gases for the agreement to enter into force.

${ }^{2} \mathrm{CO}_{2}$ emissions related to residential activity are attributed to, e.g., fossil fuels burned for heat, the use of products containing greenhouse gases, the handling of waste, and to recreational transportation such as use of passenger cars, sport utility vehicles, pickup trucks, and minivans. A smaller fraction of $\mathrm{CO}_{2}$ emissions comes from other modes of transportation, e.g., freight trucks, commercial aircraft, ships, boats, and trains, pipelines and lubricants.

${ }^{3}$ For example, OECD (2014) pp. 135-160, reports: Per litre total taxation (VAT + excise) on premium unleaded gasoline: Australia 0.51, Austria 0.95, Canada 0.39, Germany 1.20, Greece 1.29, Japan 0.65, Norway 1.47, Sweden 1.26, Switzerland 0.93, the U.K. 1.25, the U.S. 0.14. Per litre total taxation (VAT + excise) on light fuel oil for households: Austria 0.35, Denmark 0.95, Germany 0.25, Hungary 0.88, Israel 1.1, Korea 0.21, the Netherlands 0.81, Norway 0.63, Sweden 1.01, the U.K. 0.37. Taxes on sales and registration of motor vehicles: Austria VAT 20\% + New Registration Tax (fuel efficiency, $\mathrm{CO}_{2}$ emissions, polluting emissions), Belgium $V A T 21 \%+$ Entry into Service Tax (age, engine power, $\mathrm{CO}_{2}$ emissions, type of fuel gas), Germany VAT 19\%, Iceland VAT 25.5\% + Vehicle registration Fee $\left(\mathrm{CO}_{2}\right.$ emissions, electric propulsion), the Netherlands VAT $21 \%+$ Registration Tax $\left(\mathrm{CO}_{2}\right.$ emissions, motor fuel, value, electric propulsion), Norway VAT 25\% + Registration Tax (engine performance, $\mathrm{CO}_{2}$ emissions, $\mathrm{NOx}$ emissions, type of fuel, electric propulsion), Spain VAT $21 \%$ + Vehicle Registration Tax $\left(\mathrm{CO}_{2}\right.$ emissions), the US gas guzzler tax (fuel efficiency).
} 
that do not generate revenues such as environmental standards, since they can also allow for the funding of public sector activities to protect the environment, i.e., public pollution abatement. Related to this issue of public pollution abatement, considerable evidence, first, shows that governments spend a considerable portion of their tax revenues for, so called, pollution and abatement control $(P A C)$ activities, e.g., Linster and Zegel (2007) $]^{4}$ Second, suggests that, particularly in developed economies, (i) environmental factors rather than income growth have a more profound effect on residents well-being, and (ii) for the well-being of their citizens public sector spending for the provision of non-consumption public goods, such as ensuring protection and improvement of the environment, is more important than public spending related to economic growth. In this respect, several studies conclude that higher marginal welfare gains occur with increased public expenditures on environmental improvements, e.g., cleaner air and water, increased amount of waste recycling, rather than, e.g., on educational goods, e.g., Rehdanz and Maddison (2005), Welsch (2006), Ng (2008), Ong and Quah (2014).

The complexity of the various national tax systems, the recorded difficulties in many countries to monitor and collect tax revenue, the rapid growth of cross-border electronic trade, and sales of services, have put severe restraints on the enforceability of the destination-based $(D P)$ commodity taxation, which levies commodity taxes in the jurisdiction of final consumption and relies on border tax adjustments. Because of the above, quite often destination-based taxes are held accountable for various administrative complexities such as double taxation, and uncertainty for businesses and fiscal authorities, e.g., see OECD (2014) pp. 25-28. Instead, an alternative system of levying commodity taxes in the jurisdiction of production, the so-called origin principle $(O P)$ has been discussed in public policy debates.$^{5}$ Naturally, given these two systems of international commodity taxation, various policy dilemmas, such as, "where should commodity taxes be levied?", "should commodity taxes be set independently by national governments or should they be harmonized across countries?", puzzle policy makers and theorists.

\subsection{Contribution to the literature}

To the best of our knowledge, no study raises the issue of destination vs. origin-based international commodity taxation, in the presence of consumption generated cross-border pollution and public pollution abatement ${ }^{6}$ To this end, we construct a perfectly competitive three-country model

\footnotetext{
${ }^{4}$ The authors establish that aside of private sector pollution abatement activity, governments and international organizations undertake pollution abatement and control $(P A C)$ policies. They report, among other things, that during 1990-2004 for most countries public expenditures accounted for about $40-60 \%$ of total $P A C$ expenditures. Public $P A C$ expenditures as a percentage of total $P A C$ expenditures averaged $55 \%$ in Canada, Finland, France and Korea, $77 \%$ in Germany, $35 \%$ in Japan, and $40 \%$ in the US.

${ }^{5}$ As noted in OECD (2014), p. 24, "... The key economic difference between the two principles is that the destination principle places all firms competing in a jurisdiction on an even footing whereas the origin principle places consumers in different jurisdictions on even footing..."

${ }^{6}$ Related to pollution externalities, the issue of international tax competition has been examined only in the presence of production generated pollution. Cremer and Gahvari (2006), in a perfectly competitive model of two identical small open economies set conditions under which either the $(D P)$ or the $(O P)$ taxation regime can Pareto-dominate the other in the presence of such an environmental externality. A limited literature considers the environmental and welfare implications of consumption taxes in the presence of local or cross-border consumption generated pollution,
} 
producing three traded goods, where the consumption generates transboundary pollution which adversely affects households' utility. Governments levy consumption taxes on the basis of either the destination or origin-principle. Revenue from taxation is either lump-sum distributed, or finances the provision of public pollution abatement. The key result of our study is that with public pollution abatement, the non-cooperative equilibrium origin-based consumption taxes are set efficiently. It is important to note that this result holds not only in the context of fully symmetric countries, but also in the case of non-symmetric countries where households have identical incomes and preferences, or with identical homothetic preferences. The rationale is the following. A higher origin based consumption tax by one country, affects the other country's welfare negatively due to the reduction of the consumption of the taxed commodity, and positively due to the adverse effect on pollution. Evaluated at the Nash equilibrium, these two externalities cancel each other out. On the contrary, the non-cooperative equilibrium destination-based consumption taxes are inefficiently set.

\subsection{Literature review}

The long standing literature on international tax competition examines various aspects of the $D P$ and $O P$ taxation principles, e.g., welfare dominance of the one over the other, efficiency of decentralized tax setting under each regime, employment and revenue implications, without, however, considering consumption generated pollution.

In the context of models of perfect competition, a general result is that under the $D P$, and when countries are small in world commodity markets, non-cooperatively chosen commodity taxes are set efficiently. Under the $O P$, the non-cooperatively chosen commodity taxes are set inefficiently low due to a fundamental tax base externality (one region's higher tax increases the tax base of the other) $]^{7}$ For example, among others, Mintz and Tulkens (1986) conclude that under the $O P$, and in the absence of interregional public goods spillovers, the Nash, non-cooperative fiscal equilibrium is inefficient 8 Lockwood (2001) in a general equilibrium model analyzes commodity tax competition under the $D P$ and $O P$ with and without international factor mobility. He shows, among other things, that (i) in the presence of international factor mobility, destination-based Nash equilibrium taxes are second-best efficient, and (ii) under the origin principle the tax base (fiscal) externality can be of any sign depending on the relationship between the private goods in consumption (i.e., complements or substitutes).

Other studies examining the welfare ranking of the two taxation principles, include Keen and Wildasin (2004), who conclude that Pareto efficient international taxation may require production

e.g., Beghin et al. (1997), Gulati and Roy (2008), Lai and Hu (2008), Haibara and Ohta (2011), Chao et al. (2012). Chao and $\mathrm{Yu}$ (2015) in the context of a small open economy examine the environmental implications of tariff and consumption tax reforms under destination and origin-based tax principles.

${ }^{7}$ In the framework of imperfectly competitive open economy models, the issue of efficiency of the destination vs. origin-based commodity taxation has been examined, among others, by Keen and Lahiri (1998), Lockwood (2001), Haufler et al. (2005), Haufler and Pflüger (2007), and Behrens et al. (2009).

${ }^{8}$ Kanbur and Keen (1993) in a single commodity partial equilibrium model of $(D P)$ tax-competition between two countries, conclude that differences in their size (population) exacerbate the inefficiencies of non-cooperative behavior, harming them both. 
inefficiencies in the allocation of world resources. As a result, $O P$ consumption taxes may be superior to $D P$ taxes, source-based taxation of capital income may be superior to residence-based taxation, and tariff on trade flows may dominate free-trade. Moriconi and Sato (2009) in a model of two symmetric small open economies examine the impact of commodity tax competition on welfare and employment under $D P$ and $O P$, in the presence of unemployment due to a rigid nominal wage. Among their results, under $D P$ the non-cooperative equilibrium taxes are higher than the optimal level, while under $O P$ the results are ambiguous.

\section{The Model}

We consider a world of three open economies, Home, Foreign and the Rest of the World $(R O W)$. Variables of Foreign are denoted by an asterisk $(*)$. Home and Foreign constitute an economic union vis-a-vis $R O W$. A representative household resides in each country consuming three internationally traded commodities. A numeraire commodity " 0 " is produced by all three countries, and is exported by $R O W$ to Home and Foreign. By assumption, the numeraire commodity is not traded between Home and Foreign. A commodity "1", is produced by Home and $R O W$, and Home exports this good to Foreign and the $R O W$. A commodity "2" is produced by Foreign and $R O W$, and Foreign exports this good to Home and the ROW 9 Consumption of the numeraire commodity " 0 " is a clean activity in all countries, but one unit of consumption of commodities "1" and "2" generates one unit of pollution. Consumption generated pollution is transboundary affecting negatively the utility of households in Home and Foreign 10 The representative household in a country derives utility from the consumption of goods and from clean environment.

Throughout the analysis it is assumed that Home and Foreign are small open economies relative to the $R O W$, in the sense that their tax policies do not affect the world prices of the three goods. Moreover, trade of Home and Foreign, respectively, with $R O W$ is free and untaxed. That is, neither country levies any tax on its exports to $R O W$, or a tariff on imports of the numeraire commodity "0" from it. Because of these assumptions, producers prices in Home and Foreign are constant and without loss of generality, for the rest of the analysis, are set equal to one 11 Production of

\footnotetext{
${ }^{9}$ This pattern of production specialization implies that the economic union is a net exporter of goods "1" and " 2 " to $R O W$ and a net importer of the numeraire. This pattern of production specialization is in complete accordance with the relevant literature of international commodity taxation. For example, following Haufler (1994), this pattern of production and trade ensures that (i) no country can simultaneously export and import the same commodity, and (ii) a country's multilateral trade must be balanced. Lockwood (2001, p. 284) introduces this assumption allowing for complete specialization at all producer prices, constant returns to scale production technologies, and labor being the only input of production, with one unit of labor required to produce one unit of each commodity. In Haufler and Pflüger (2007, p. 454) labor is the only factor of production, and each country posses " ... an unmodelled and unremunareted additional factor ... which is specific to sectors $x$ and $y$...". Moriconi and Sato (2009) follow Lockwood's rationale for a similar pattern of production in the presence of unemployment.

${ }^{10} \mathrm{~A}$ more general specification of consumption generated pollution could allow, for example, a unit of consumption of commodities "1" and "2" to generate $\alpha_{i}, i=1,2$, units of pollution in Home, and $\alpha_{i}^{*}$ units of pollution in Foreign. Such a specification complicates unnecessarily the analytical exposition without altering significantly the results. Thus, we let $\alpha_{i}=\alpha_{i}^{*}=1$.

${ }^{11}$ The assumption of fixed producer prices is due to the small country assumption and the structure of production. It is in accordance with the literature of international commodity taxation. For example, in Lockwood (2001, p.
} 
goods in all countries is assumed a non-polluting and untaxed activity, and is represented by the Gross Domestic Product $(G D P)$ function. The GDP function depends on producer prices and supplies of factors of production. Given our assumptions of constant producers prices and fixed factor supplies, Home and Foreign's GDP functions are denoted by $R($.$) and R^{*}($.$) , respectively.$

Let $e\left(1, q_{1}, q_{2}, r, u\right)$ be the minimum expenditure function for Home's representative household which shows the minimum expenditure required to attain a level of utility $u$ at given consumer prices $q_{1}$ and $q_{2}$, and level of pollution $r$, to be defined later on. With $e_{q_{i}}\left(=\partial e / \partial q_{i}\right)$ we denote the $i^{\text {th }}$ commodity's compensated demand function, where $i=1,2, e_{u}$ is the reciprocal of the marginal utility of income, and $e_{r}$ denotes the marginal willingness to pay for pollution reduction. The $e($. function is strictly concave in consumer prices, i.e., $e_{q_{1} q_{1}}$ and $e_{q_{2} q_{2}}$ are negative, and commodities "1" and "2" can be substitutes (complements) in consumption, i.e., $e_{q_{1} q_{2}}=e_{q_{2} q_{1}}>0(<0)$.12 It is assumed that all income effects fall on the numeraire commodity, thus, $e_{q_{1} u}=e_{q_{2} u}=0$ and that the level of pollution does not affect consumption, i.e., $e_{q_{i} r}=0{ }^{13}$ Equivalently, the minimum expenditure function for Foreign's household is given by $e^{*}\left(1, q_{1}^{*}, q_{2}^{*}, r^{*}, u^{*}\right)$, with similar properties applying.

An active government in Home and Foreign taxes the consumption of polluting commodities at a specific rate $t$ in Home and $t^{*}$ in Foreign according to the destination, i.e., $t_{d}$ and $t_{d}^{*}$, or origin, i.e., $t_{o}$ and $t_{o}^{*}$, principle of commodity taxation. For simplicity we also assume uniform destination or origin-based consumption taxes in Home and Foreign on all commodities instead of commodityspecific taxes on each commodity in each country. Revenue from commodity taxation in Home and Foreign is either lump-sum distributed to the representative household, or it is used to finance public pollution abatement, by purchasing a public abatement commodity $g\left(g^{*}\right)$ at a fixed price.

\section{Commodity tax competition without public pollution abate- ment}

We begin by examining the welfare effects and the efficiency of decentralized setting of consumption taxes under the two tax principles in the presence of cross-border pollution, but without public pollution abatement. Thus, consumption tax revenues are lump-sum redistributed to the countries representative households. Overall pollution in Home and Foreign equals total consumption of the two polluting goods in both countries. That is 14

$285)$, producers prices are constant and set equal to one, due to perfect international labor mobility (assumption A1, p. 284), and due to same wages in the two countries, which are set equal to one. In Moriconi and Sato (2006, 2009) due to the fixed factor prices, producers prices are also fixed. Finally, Haufler and Pflüger (2007) by choice of units, fix to one the wage rate and producer prices in the two countries.

${ }^{12}$ All subscripts denote partial derivatives, e.g., $e_{q_{1} q_{1}}=\partial e_{q_{1}} / \partial q_{1}$.

${ }^{13}$ Assuming $e_{q_{i} r}=0$ implies that the polluting good and pollution (clean environment) are independent in consumption, e.g., see Keen and Kotsogiannis (2014).

${ }^{14} \mathrm{~A}$ more general specification for pollution could, for example, be $r=e_{q_{1}}+e_{q_{2}}+\theta\left(e_{q_{1}^{*}}^{*}+e_{q_{2}^{*}}^{*}\right)$, where $\theta$ is the rate of cross-border pollution. If $\theta=0$, pollution is local, while if $\theta=1$, as assumed here, pollution is perfectly trasboundary. 


$$
r=r^{*}=e_{q_{1}}(.)+e_{q_{2}}(.)+e_{q_{1}^{*}}^{*}(.)+e_{q_{2}^{*}}^{*}(.) .
$$

Note that since tax policies by Home and Foreign do not affect world commodity prices, consumption in $R O W$ is unaffected by changes in $t_{j}$ and $t_{j}^{*}, j=d, o$. Consumption tax policies in Home and Foreign affect only the levels of consumption of commodities "1" and "2" in these two countries.

\subsection{Destination-based consumption taxes}

When consumption is taxed according to the destination principle, consumer prices in Home are $q_{1}=1+t_{d}$ and $q_{2}=1+t_{d}$, and in Foreign are $q_{1}^{*}=1+t_{d}^{*}$ and $q_{2}^{*}=1+t_{d}^{*}$. Consumption tax revenue in Home and Foreign are respectively denoted by $t_{d}\left(e_{q_{1}}+e_{q_{2}}\right)$ and $t_{d}^{*}\left(e_{q_{1}^{*}}^{*}+e_{q_{2}^{*}}^{*}\right)$. The countries income-expenditure identities require that total private spending on commodities must equal income from production plus the consumption tax revenues. That is,

$$
\begin{aligned}
e\left(1, q_{1}, q_{2}, r, u\right) & =R(.)+t_{d}\left(e_{q_{1}}+e_{q_{2}}\right), \\
e^{*}\left(1, q_{1}^{*}, q_{2}^{*}, r^{*}, u^{*}\right) & =R^{*}(.)+t_{d}^{*}\left(e_{q_{1}^{*}}^{*}+e_{q_{2}^{*}}^{*}\right) .
\end{aligned}
$$

Equations (1) and (2) constitute a system of three equations in $u, u^{*}$, and $r$, in terms of the policy parameters $\left(t_{d}, t_{d}^{*}\right)$. We examine the effects of changes in $t_{d}$ and $t_{d}^{*}$ on Home's welfare. The effects on Foreign's welfare follow equivalently. Totally differentiating Home's income-expenditure identity we obtain:

$$
e_{u} d u=-e_{r} d r+t_{d}\left(Z_{q_{1}}+Z_{q_{2}}\right) d t_{d}
$$

where $Z=e_{q_{1}}+e_{q_{2}}, Z_{q_{1}}=e_{q_{1} q_{1}}+e_{q_{2} q_{1}}$ and $Z_{q_{2}}=e_{q_{1} q_{2}}+e_{q_{2} q_{2}}$. For example, $Z_{q_{1}}$ captures the changes in Home's consumption of commodities "1" and "2" due to changes in the consumer price of good 1 as a result of changes in $t_{d}$. By the properties of the expenditure function $\left(Z_{q_{1}}+Z_{q_{2}}\right)$ is negative 15

Total differentiation of equation (1) yields

$$
d r=\left(Z_{q_{1}}+Z_{q_{2}}\right) d t_{d}+\left(Z_{q_{1}^{*}}^{*}+Z_{q_{2}^{*}}^{*}\right) d t_{d}^{*}
$$

Since $\left(Z_{q_{1}}+Z_{q_{2}}\right)$ and $\left(Z_{q_{1}^{*}}^{*}+Z_{q_{2}^{*}}^{*}\right)$ are negative, an increase in Home or Foreign's destinationbased consumption tax lowers consumption of both goods and thus consumption generated pollution in the country, i.e., $\left(d r / d t_{d}\right)<0$ and $\left(d r / d t_{d}^{*}\right)<0$. Substituting equation (4) into (3), overall

\footnotetext{
${ }^{15}$ From the properties of the expenditure function we know that $q_{0} e_{q_{1} q_{0}}+q_{1} e_{q_{1} q_{1}}+q_{2} e_{q_{1} q_{2}}=0$, and $e_{q_{i} q_{j}}=e_{q_{j} q_{i}}$. Since producer prices of both goods equal 1 and consumption taxes are the same, we have $q_{1}=q_{2}=q$. Thus $q_{0} e_{q_{1} q_{0}}+q\left(e_{q_{1} q_{1}}+e_{q_{1} q_{2}}\right)=q_{0} e_{q_{1} q_{0}}+q Z_{q_{1}}=0$. Similarly, $q_{0} e_{q_{2} q_{0}}+q Z_{q_{2}}=0$. Thus, $q\left(Z_{q_{1}}+Z_{q_{2}}\right)=-q_{0}\left(e_{q_{0} q_{1}}+e_{q_{0} q_{2}}\right)$, which can be written as $q\left(Z_{q_{1}}+Z_{q_{2}}\right)=\frac{q_{0}}{q}\left(q_{0} e_{q_{0} q_{0}}\right)<0$.
} 
changes in the level of Home's welfare $(u)$ due to changes in $t_{d}$ and $t_{d}^{*}$ are given as follows:

$$
e_{u} d u=-\left(Z_{q_{1}}+Z_{q_{2}}\right)\left(e_{r}-t_{d}\right) d t_{d}-\left(Z_{q_{1}^{*}}^{*}+Z_{q_{2}^{*}}^{*}\right) e_{r} d t_{d}^{*} .
$$

Similar procedure yields the changes in Foreign's welfare $\left(u^{*}\right)$ as follows:

$$
e_{u^{*}}^{*} d u^{*}=-\left(Z_{q_{1}^{*}}^{*}+Z_{q_{2}^{*}}^{*}\right)\left(e_{r^{*}}^{*}-t_{d}^{*}\right) d t_{d}^{*}-\left(Z_{q_{1}}+Z_{q_{2}}\right) e_{r^{*}}^{*} d t_{d}
$$

where $Z_{q_{1}^{*}}^{*}=e_{q_{1}^{*} q_{1}^{*}}^{*}+e_{q_{2}^{*} q_{1}^{*}}^{*}$ and $Z_{q_{2}^{*}}^{*}=e_{q_{1}^{*} q_{2}^{*}}^{*}+e_{q_{2}^{*} q_{1}^{*}}^{*}$. An increase in the own destination-based consumption tax improves (worsens) Home's welfare if it is lower (higher) than the household's marginal willingness to pay for pollution abatement, e.g., $\left(-e_{r}+t_{d}\right)<0(>0)$. A higher destination-based tax by Foreign, improves Home's welfare. Intuitively, a higher consumption tax by Foreign reduces its consumption, thus pollution, affecting Home's welfare positively. Similar results are derived for changes in $t_{d}$ and $t_{d}^{*}$ on Foreign's welfare.

\subsubsection{Efficiency of the Nash equilibrium}

The above results can be used to derive the countries Nash equilibrium destination-based consumption taxes, and to evaluate the efficiency of the Nash equilibrium taxes vis-a-vis the cooperative equilibrium taxes. Setting $e_{u}\left(d u / d t_{d}\right)=0$ and $e_{u^{*}}^{*}\left(d u^{*} / d t_{d}^{*}\right)=0$, in equations (5) and (6), the Nash equilibrium destination-based consumption taxes are given as follows:

$$
t_{d}^{N}=e_{r} \quad \text { and } \quad t_{d}^{* N}=e_{r^{*}}^{*}
$$

In the absence of consumption generated pollution, i.e., $e_{r}=e_{r^{*}}^{*}=0$, it is evident that $t_{d}^{N}=$ $t_{d}^{* N}=0$. In the presence of consumption generated pollution, the Nash equilibrium policy is a positive destination-based consumption tax, i.e., $t_{d}^{N}>0$ and $t_{d}^{* N}>0$. Intuitively, in the absence of pollution, a higher destination-based consumption tax reduces consumption of commodities "1" and "2", and the government's consumption tax revenue. Since the latter is lump-sum redistributed to the country's household, its income and welfare fall. Therefore the Nash equilibrium destinationbased consumption tax is zero. In the presence of cross-border pollution, a higher $t_{d}$ in addition to the previous effect, it also leads to a reduction in consumption generated pollution, which entails a positive impact on the household's welfare. Thus, in the presence of pollution, the Nash equilibrium destination-based consumption tax is positive.

We compare the Nash equilibrium destination-based consumption tax policy to the cooperative destination-based consumption tax policy $t_{d}^{C}$ and $t_{d}^{* C}$. The cooperative equilibrium destinationbased consumption taxes are determined by maximizing the countries' joint welfare functions. That is, by setting $e_{u}\left(d u / d t_{d}\right)+e_{u^{*}}^{*}\left(d u^{*} / d t_{d}\right)=0$, and $e_{u}\left(d u / d t_{d}^{*}\right)+e_{u^{*}}^{*}\left(d u^{*} / t_{d}^{*}\right)=0$. Using equations (5) and (6) in the presence of consumption generated cross-border pollution, the cooperative consumption taxes are given by:

$$
t_{d}^{C}=t_{d}^{* C}=e_{r}+e_{r^{*}}^{*}
$$


Comparing equations (7) and (8) reveals that $t_{d}^{C}>t_{d}^{N}$. Alternatively, to ascertain whether the Nash equilibrium taxes are higher or lower than the cooperative equilibrium taxes, we evaluate the slopes of these joint welfare functions at Nash equilibrium. Doing so, it suffices to determine the sign of the terms $e_{u^{*}}^{*}\left(d u^{*} / d t_{d}\right)$ and $e_{u}\left(d u / d t_{d}^{*}\right)$, since at Nash equilibrium $e_{u}\left(d u / d t_{d}\right)=e_{u^{*}}^{*}\left(d u^{*} / t_{d}^{*}\right)=0$. For example, substituting $t_{d}^{* N}$ from equations (7) into equation (6), we obtain:

$$
\left.e_{u^{*}}^{*} \frac{d u^{*}}{d t_{d}}\right|_{N}=-e_{r^{*}}^{*}\left(Z_{q_{1}}+Z_{q_{2}}\right)
$$

Given that $\left(Z_{q_{1}}+Z_{q_{2}}\right)<0$, then $\left.e_{u^{*}}^{*} \frac{d u^{*}}{d t_{d}}\right|_{N}>0$. This implies that the slope of the joint welfare function at Nash equilibrium is positive. Thus, the Nash equilibrium destination-based consumption tax is lower than the corresponding cooperative equilibrium tax. Intuitively, an increase in $t_{d}$ affects Foreign's welfare only through the changes in pollution. This effect is called environmental externality. That is, an increase in $t_{d}$ decreases consumption of both commodities "1" and "2". Then, overall consumption generated pollution in Home and Foreign falls 16 This positive environmental externality of the higher $t_{d}$ on Foreign's welfare is not considered by Home, when the latter country acts Nash (non-cooperatively). Thus, in this case, its Nash equilibrium destination-based consumption tax is smaller than the corresponding cooperative level. Note that in the absence of consumption generated cross-border pollution, we obtain the standard result of the literature that the Nash equilibrium taxes under the destination principle are efficient for small open economies (see Lockwood 2001, Haufler and Pflüger 2007). Based on the results of this section, we state the following proposition.

Proposition 1 Consider two small open economies with consumption generated cross-border pollution.

(i) The Nash (decentralized) equilibrium destination-based consumption tax is equal to the marginal environmental damage of pollution.

(ii)The Nash equilibrium destination-based consumption taxes are lower than the corresponding cooperative tax levels.

\subsection{Origin-based consumption taxes}

Now we consider the origin-based consumption taxes. As it was stated earlier Home and Foreign tax only the production which is used for consumption in Home and Foreign. That is, Home taxes the production of good 1, while Foreign taxes the production of good 2 which are used for consumption in Home and Foreign. Their exports to $R O W$ are completely untaxed. Following the relevant literature, e.g., Haufler (1994), we refer to this principle of commodity taxation as "restricted origin principle" ${ }^{17}$ With origin-based consumption taxes, prices are $q_{1}=1+t_{o}$ and $q_{2}=1+t_{o}^{*}$ in Home, and $q_{1}^{*}=1+t_{o}$ and $q_{2}^{*}=1+t_{o}^{*}$ in Foreign. That is, $q_{1}=q_{1}^{*}$ and $q_{2}=q_{2}^{*}$.

\footnotetext{
${ }^{16}$ Combining equations $[4]$ and $[6]$ we get that $e_{u^{*}}^{*}\left(d u^{*} / d t_{d}\right)=-e_{r}^{*}\left(d r / d t_{d}\right)$, where $\left(d r / d t_{d}\right)=\left(Z_{q_{1}}+Z_{q_{2}}\right)$.

${ }^{17}$ In Haufler (1994), the two union countries apply the origin principle of commodity taxation for their mutual trade, and the destination principle for the trade between each one of them and the $R O W$.
} 
Tax revenue for Home consists of tax revenue from consumption of good 1 in Home and Foreign, i.e., $t_{o}\left(e_{q_{1}}+e_{q_{1}}^{*}\right)$ and tax revenue for Foreign consists of tax revenue from consumption of good 2 in Home and Foreign, i.e., $t_{o}^{*}\left(e_{q_{2}}+e_{q_{2}^{*}}^{*}\right)$. The countries income-expenditure identities in this case are:

$$
\begin{aligned}
e\left(1, q_{1}, q_{2}, r, u\right) & =R(.)+t_{o} E_{q_{1}}\left(q_{1}, q_{2}, r, r^{*}, u, u^{*}\right), \\
e^{*}\left(1, q_{1}^{*}, q_{2}^{*}, r^{*}, u^{*}\right) & =R^{*}(.)+t_{o}^{*} E_{q_{2}}\left(q_{1}, q_{2}, r, r^{*}, u, u^{*}\right),
\end{aligned}
$$

where $E_{q_{1}}=e_{q_{1}}+e_{q_{1}^{*}}^{*}$ and $E_{q_{2}}=e_{q_{2}}+e_{q_{2}^{*}}^{*}$ are, respectively, the aggregate consumption for commodity "1" and "2" by the two countries. Equations (1) and (10) constitute a system of three equations in $u, u^{*}$, and $r$, in terms of the policy parameters $t_{o}$ and $t_{o}^{*}$. We examine the effects of changes in $t_{o}$ and $t_{o}^{*}$ on Home's welfare. The results for Foreign, follow similarly. Totally differentiating Home's income-expenditure identity we obtain:

$$
e_{u} d u=-e_{r} d r+\left(e_{q_{1}^{*}}^{*}+t_{o} E_{q_{1} q_{1}}\right) d t_{o}+\left(-e_{q_{2}}+t_{o} E_{q_{1} q_{2}}\right) d t_{o}^{*}
$$

where $E_{q_{1} q_{1}}=e_{q_{1} q_{1}}+e_{q_{1}^{*} q_{1}^{*}}^{*}<0$, and $E_{q_{1} q_{2}}=e_{q_{1} q_{2}}+e_{q_{1}^{*} q_{2}^{*}}^{*} \gtrless 0$. Total differentiation of equation (1) yields

$$
d r=\left(E_{q_{1} q_{1}}+E_{q_{2} q_{1}}\right) d t_{o}+\left(E_{q_{2} q_{2}}+E_{q_{1} q_{2}}\right) d t_{o}^{*}
$$

where $E_{q_{2} q_{2}}=e_{q_{2} q_{2}}+e_{q_{2}^{*} q_{2}^{*}}^{*}<0$.

Substituting equation (12) into equation (11), overall changes in the level of Home's welfare $(u)$ due to changes in $t_{o}$ and $t_{o}^{*}$ are given as follows:

$$
\begin{aligned}
e_{u} d u & =\left[\left(-e_{r}+t_{o}\right) E_{q_{1} q_{1}}-e_{r} E_{q_{2} q_{1}}+e_{q_{1}^{*}}^{*}\right] d t_{o} \\
& +\left[\left(-e_{r}+t_{o}\right) E_{q_{1} q_{2}}-e_{r} E_{q_{2} q_{2}}-e_{q_{2}}\right] d t_{o}^{*} .
\end{aligned}
$$

Similar procedure for changes in Foreign's welfare $\left(u^{*}\right)$ due to changes in $t_{o}$ and $t_{o}^{*}$ yields:

$$
\begin{aligned}
e_{u^{*}}^{*} d u^{*} & =\left[\left(-e_{r^{*}}^{*}+t_{o}^{*}\right) E_{q_{2} q_{1}}-e_{r^{*}}^{*} E_{q_{1} q_{1}}-e_{q_{1}^{*}}^{*}\right] d t_{o} \\
& +\left[\left(-e_{r^{*}}^{*}+t_{o}^{*}\right) E_{q_{2} q_{2}}-e_{r^{*}}^{*} E_{q_{1} q_{2}}+e_{q_{2}}\right] d t_{o}^{*}
\end{aligned}
$$

Sufficient, but not necessary conditions, for a higher origin-based consumption tax to improve a country's own welfare are that: (i) the consumption tax is smaller than the marginal environmental damage of pollution in the country, i.e., $\left(-e_{r}+t_{o}\right)<0$ and $\left(-e_{r^{*}}^{*}+t_{o}^{*}\right)<0$, and (ii) commodities "1" and "2" are complements in consumption, i.e., $E_{q_{1} q_{2}}=E_{q_{2} q_{1}}<0$. However, a higher tax by one country still exerts an ambiguous impact on the other's welfare. 


\subsubsection{Efficiency of the Nash equilibrium}

We use the above results to derive the countries Nash equilibrium origin-based consumption taxes, and to evaluate the efficiency of the Nash policies vis-a-vis the setting of cooperative equilibrium taxes. Setting $e_{u}\left(d u / d t_{0}\right)=0$ and $e_{u^{*}}^{*}\left(d u^{*} / d t_{o}^{*}\right)=0$, in equations (13) and (14), the Nash equilibrium origin-based consumption taxes are given as follows:

$$
t_{o}^{N}=E_{q_{1} q_{1}}^{-1}\left[e_{r}\left(E_{q_{1} q_{1}}+E_{q_{2} q_{1}}\right)-e_{q_{1}^{*}}^{*}\right], \quad t_{o}^{* N}=E_{q_{2} q_{2}}^{-1}\left[e_{r}^{*}\left(E_{q_{2} q_{2}}+E_{q_{1} q_{2}}\right)-e_{q_{2}}\right] .
$$

In the absence of consumption generated pollution, equations 15 indicate that, the Nash equilibrium policy is a positive origin-based consumption tax, i.e., $t_{o}^{N}=-E_{q_{1} q_{1}}^{-1} e_{q_{1}^{*}}^{*}>0$ and $t_{o}^{* N}=$ $-E_{q_{2} q_{2}}^{-1} e_{q_{2}}>0$. Intuitively, a higher origin-based consumption tax entails two effects on a country's own welfare. First, it increases tax revenue for given consumption levels, which positively affects own welfare, and second it lowers tax revenue due to lower consumption in the two countries, which negatively affects own welfare ${ }^{18}$ Thus, in the absence cross-border consumption generated pollution, the Nash equilibrium origin-based consumption tax is positive. In the presence of cross-border pollution, however, a higher origin-based consumption tax lowers the sum of consumptions of the two goods in the two countries, therefore it lowers overall consumption generated pollution, and raises welfare if $\left(E_{q_{1} q_{1}}+E_{q_{2} q_{1}}\right)<0$ and $\left(E_{q_{2} q_{2}}+E_{q_{1} q_{2}}\right)<0,19$ For example, an increase in the origin-based consumption tax on good 1 reduces the sum of consumptions of goods 1 and 2 in the two countries, and thus total pollution falls. Thus, the origin-based consumption tax is positive, and higher to its Nash equilibrium rate when consumption generated pollution does not exist.

Next, we compare the Nash equilibrium origin-based consumption tax policy to the cooperative origin-based consumption tax policy. The cooperative equilibrium origin-based consumption taxes $t_{o}^{C}$ and $t_{o}^{* C}$ are determined by maximizing the countries joint welfare functions. That is, by simultaneously solving $e_{u}\left(d u / d t_{o}\right)+e_{u^{*}}^{*}\left(d u^{*} / d t_{o}\right)=0$, and $e_{u}\left(d u / d t_{o}^{*}\right)+e_{u^{*}}^{*}\left(d u^{*} / t_{o}^{*}\right)=0$. Using equations (13) and (14) in the presence of consumption generated cross-border pollution the cooperative consumption taxes under the origin principle of taxation are again given by equation (8) 20

To ascertain whether the cooperative equilibrium origin-based taxes are higher or lower than the corresponding Nash equilibrium taxes, we evaluate the slopes of these joint welfare functions at Nash equilibrium. Doing so, it suffices to determine the sign of the terms $e_{u^{*}}^{*}\left(d u^{*} / d t_{o}\right)$ and $e_{u}\left(d u / d t_{o}^{*}\right)$, since at Nash equilibrium $e_{u}\left(d u / d t_{o}\right)=e_{u^{*}}^{*}\left(d u^{*} / t_{o}^{*}\right)=0$. For example, consider the case of Home. Substituting $t_{o}^{* N}$ from equations 15 into the expression for $e_{u^{*}}^{*}\left(d u^{*} / d t_{o}\right)$ in equation (14), we obtain:

\footnotetext{
${ }^{18}$ In the absence of consumption generated pollution, equations 13 and 14 reduce to $e_{u} d u=\left(e_{q_{1}^{*}}^{*}+t_{o} E_{q_{1} q_{1}}\right) d t_{o}$, and $e_{u^{*}}^{*} d u^{*}=\left(e_{q_{1}}+t_{o}^{*} E_{q_{2} q_{2}}\right) d t_{o}^{*}$.

${ }^{19}$ This implies that goods 1 and 2 either are complements, or if they are substitutes then the own price effect dominates the cross-price effect, i.e., $-E_{q_{1} q_{1}}>E_{q_{2} q_{1}}$.

${ }^{20}$ The cooperative taxes under the origin-based taxation principle are the same as those under the destination-based principle, since the two regimes are equivalent under cooperative taxation.
} 


$$
\left.e_{u^{*}}^{*} \frac{d u^{*}}{d t_{o}}\right|_{N}=-e_{q_{1}^{*}}^{*}-E_{q_{2} q_{2}}^{-1} E_{q_{2} q_{1}} e_{q_{2}}-e_{r^{*}}^{*} \bar{E}_{q_{1} q_{1}},
$$

where $\bar{E}_{q_{1} q_{1}}=E_{q_{1} q_{1}}-E_{q_{1} q_{2}} E_{q_{2} q_{2}}^{-1} E_{q_{2} q_{1}}<0$. Equation 16 indicates that the impact of $t_{o}^{N}$ on Foreign's welfare $\left(u^{*}\right)$ is through three effects. Specifically, a higher $t_{o}$ (i) lowers Foreign's consumption of commodity "1" exerting a negative impact on its welfare. This effect is called private consumption externality (i.e., $-e_{q_{1}^{*}}^{*}<0$ ), (ii) by affecting tax revenue for a given tax rate i,e., $-E_{q_{2} q_{2}}^{-1} E_{q_{2} q_{1}} e_{q_{2}} \lessgtr 0$ depending on whether commodities "1" and "2" are complements or substitutes in consumption. This effect is called public revenue externality. For example, if they are complements, i.e., $E_{q_{2} q_{1}}<0$, a higher $t_{o}$ by Home also reduces aggregate consumption of commodity "2", thus Foreign's consumption tax revenue and welfare; and (iii) increases Foreign welfare by reducing total consumption and pollution. This effect is the environmental externality, i.e., $-e_{r^{*}}^{*} \bar{E}_{q_{1} q_{1}}>0.21$ In the absence of cross-border consumption pollution equation $(16)$ reduces to $\left.e_{u^{*}}^{*} \frac{d u^{*}}{d t_{o}}\right|_{N}=-e_{q_{1}^{*}}^{*}-E_{q_{2} q_{2}}^{-1} E_{q_{2} q_{1}} e_{q_{2}}$. The latter expression along with equation (8) reproduce the standard literature result for origin-based consumption taxes in the non-pollution case. For example, Haufler and Pflüger (2007) demonstrates that (i) the cooperative equilibrium origin-based consumption taxes are zero, i.e., $t_{o}^{C}=t_{o}^{* C}=0$, and (ii) $-e_{q_{1}^{*}}^{*}-E_{q_{2} q_{2}}^{-1} E_{q_{2} q_{1}} e_{q_{2}}$ is negative. Thus, in the absence of pollution, the Nash equilibrium origin-based consumption taxes are higher than the corresponding cooperative equilibrium taxes, i.e., $t_{o}^{N}>t_{o}^{C}=0$. The presence of consumption generated cross-border pollution leads to a higher Nash and a higher cooperative equilibrium origin-based consumption taxes. Since the last RHS term of equation (16) is positive, the presence of consumption generated cross-border pollution narrows the difference between the Nash and the cooperative equilibrium tax level, or it may reverse the inequality between the two equilibrium taxes, i.e., see equations (15), (8), and (16). Based on these results we state the following Proposition.

Proposition 2 Consider two small open economies with consumption generated cross-border pollution. The Nash and cooperative equilibrium origin-based consumption taxes are higher to the corresponding taxes of the non-pollution case, and the Nash equilibrium taxes may be lower than the corresponding cooperative equilibrium tax levels.

\section{Commodity tax competition with public pollution abatement}

Now we consider the case where governments use the destination or origin-based consumption tax revenue to finance public pollution abatement. For this activity, we assume that Home and Foreign use a traded good whose price $p_{g}$ is fixed and the same for both countries. ${ }^{22}$ Assuming also that both governments maintain balanced budgets, their budget constraints are:

\footnotetext{
${ }^{21}$ From equation $\sqrt{14}$ we can write $e_{u^{*}}^{*}\left(d u^{*} / d t_{o}\right)=-e_{q_{1}^{*}}^{*}+t_{o}^{*} E_{q_{2} q_{1}}-e_{r}^{*}\left(d r / d t_{o}\right)$, where $\left(d r / d t_{o}\right)=E_{q_{1} q_{1}}+E_{q_{2} q_{1}}$. Then, substituting the value of $t_{o}^{* N}$ given by equation 15 , gives equation 16 .

${ }^{22}$ Assuming different constant unit prices of public pollution abatement in the two countries does not alter the results of the analysis.
} 


$$
p_{g} g=t_{d}\left(e_{q_{1}}+e_{q_{2}}\right) \quad \text { and } \quad p_{g} g^{*}=t_{d}^{*}\left(e_{q_{1}^{*}}^{*}+e_{q_{2}^{*}}^{*}\right)
$$

under destination-based consumption taxes, and

$$
p_{g} g=t_{o}\left(e_{q_{1}}+e_{q_{1}^{*}}^{*}\right) \quad \text { and } \quad p_{g} g^{*}=t_{o}^{*}\left(e_{q_{2}}+e_{q_{2}^{*}}^{*}\right)
$$

under origin-based consumption taxes. Furthermore, with public pollution abatement, overall pollution in the two countries becomes

$$
r=r^{*}=\left(e_{q_{1}}(.)+e_{q_{2}}(.)-g\right)+\left(e_{q_{1}^{*}}^{*}(.)+e_{q_{2}^{*}}^{*}(.)-g^{*}\right) .
$$

The two countries income-expenditure identities require that total private spending on commodities must equal income from production. That is:

$$
e\left(1, q_{1}, q_{2}, r, u\right)=R(.) \quad \text { and } \quad e^{*}\left(1, q_{1}^{*}, q_{2}^{*}, r^{*}, u^{*}\right)=R^{*}(.) .
$$

We examine the welfare effects and the efficiency of decentralized setting of destination and originbased consumption taxes in the presence of consumption generated cross-border pollution and public pollution abatement.

\subsection{Destination-based consumption taxes}

Equations (20) along with equations (17) and (19) constitute a system of five equations in $u, u^{*}, g, g^{*}$ and $r$, in terms of the policy parameters $t_{d}$ and $t_{d}^{*}$. Note that now $q_{1}=1+t_{d}, q_{2}=1+t_{d}, q_{1}^{*}=1+t_{d}^{*}$ and $q_{2}^{*}=1+t_{d}^{*}$. Totally differentiating equations (19) and (17) we obtain the effects of changes in consumption taxes on aggregate pollution as follows:

$$
\begin{aligned}
d r & =d r^{*}=\left[\left(p_{g}-t_{d}\right)\left(Z_{q_{1}}+Z_{q_{2}}\right)-\left(e_{q_{1}}+e_{q_{2}}\right)\right] p_{g}^{-1} d t_{d} \\
& +\left[\left(p_{g}-t_{d}^{*}\right)\left(Z_{q_{1}^{*}}^{*}+Z_{q_{2}^{*}}^{*}\right)-\left(e_{q_{1}^{*}}^{*}+e_{q_{2}^{*}}^{*}\right)\right] p_{g}^{-1} d t_{d}^{*} .
\end{aligned}
$$

Totally differentiating equations (20), changes in Home and Foreign's national welfare are given as:

$$
e_{u} d u=-e_{r} d r-\left(e_{q_{1}}+e_{q_{2}}\right) d t_{d}, \quad \text { and } \quad e_{u^{*}}^{*} d u^{*}=-e_{r^{*}}^{*} d r^{*}-\left(e_{q_{1}^{*}}^{*}+e_{q_{2}^{*}}^{*}\right) d t_{d}^{*} .
$$

Equation (22) shows, for example, that an increase in the destination tax of one country affects its own welfare directly by reducing its consumption and indirectly by affecting its pollution. The effect on the other country's welfare is only indirect through changes in its level of pollution. Using equation (21) in equations (22) we obtain the welfare effects of changes in taxes $t_{d}$ and $t_{d}^{*}$, on the two countries welfare as follows: 


$$
\begin{aligned}
e_{r}^{-1} p_{g} e_{u} d u & =-\left[\left(p_{g}-t_{d}\right)\left(Z_{q_{1}}+Z_{q_{2}}\right)-e_{r}^{-1}\left(e_{q_{1}}+e_{q_{2}}\right)\left(-p_{g}+e_{r}\right)\right] d t_{d} \\
& -\left[\left(p_{g}-t_{d}^{*}\right)\left(Z_{q_{1}^{*}}^{*}+Z_{q_{2}^{*}}^{*}\right)-\left(e_{q_{1}^{*}}^{*}+e_{q_{2}^{*}}^{*}\right)\right] d t_{d}^{*}, \\
e_{r^{*}}^{*^{-1}} p_{g} e_{u^{*}}^{*} d u^{*} & =-\left[\left(p_{g}-t_{d}^{*}\right)\left(Z_{q_{1}^{*}}^{*}+Z_{q_{2}^{*}}^{*}\right)-e_{r^{*}}^{*^{-1}}\left(e_{q_{1}^{*}}^{*}+e_{q_{2}^{*}}^{*}\right)\left(-p_{g}+e_{r^{*}}^{*}\right)\right] d t_{d}^{*} \\
& -\left[\left(p_{g}-t_{d}\right)\left(Z_{q_{1}}+Z_{q_{2}}\right)-\left(e_{q_{1}}+e_{q_{2}}\right)\right] d t_{d},
\end{aligned}
$$

where $Z_{q_{1}}+Z_{q_{2}}$ and $Z_{q_{1}^{*}}^{*}+Z_{q_{2}^{*}}^{*}$ are negative (see footnote 15). Equations 23 and (24) indicate that a higher own destination-based consumption tax improves a country's welfare if the price of the public abatement commodity is (i) higher than the tax level, e.g., $p_{g}>t_{d}$, and (ii) lower than the marginal willingness to pay for pollution abatement, e.g., $\left(-p_{g}+e_{r^{*}}^{*}\right)>0$. A higher destination-based consumption tax by one country improves the other's welfare.

\subsubsection{Efficiency of the Nash equilibrium}

Setting $e_{u}\left(d u / d t_{d}\right)=0$ and $e_{u^{*}}^{*}\left(d u^{*} / d t_{d}^{*}\right)=0$, in equations (23) and (24), the Nash equilibrium destination-based consumption taxes with consumption generated cross-border pollution and public pollution abatement are given as follows:

$$
\begin{aligned}
t_{d}^{N} & =p_{g}-\left(Z_{q_{1}}+Z_{q_{2}}\right)^{-1}\left(e_{q_{1}}+e_{q_{2}}\right)\left(-p_{g}+e_{r}\right), \\
t_{d}^{* N} & =p_{g}-\left(Z_{q_{1}^{*}}^{*}+Z_{q_{2}^{*}}^{*}\right)^{-1}\left(e_{q_{1}^{*}}^{*}+e_{q_{2}^{*}}^{*}\right)\left(-p_{g}^{*}+e_{r}^{*}\right) .
\end{aligned}
$$

Equations 25) indicate that the Nash equilibrium destination-based consumption taxes are positive, provided that $\left(-p_{g}+e_{r}\right) \geqslant 0$ and $\left(-p_{g}+e_{r^{*}}^{*}\right) \geqslant 0$. Furthermore, if $\left(-p_{g}+e_{r}\right)=(<) 0$ and $\left(-p_{g}+e_{r^{*}}^{*}\right)=(<) 0$, then, the Nash equilibrium destination-based consumption taxes equal (exceed) the fixed price of the public abatement commodity.

In addressing the question of whether Nash destination-based consumption taxes are equally efficient as the corresponding cooperative taxes, we proceed as previously. The cooperative equilibrium destination-based consumption taxes $t_{d}^{C}$ and $t_{d}^{* C}$ are determined by simultaneously setting $e_{u}\left(d u / d t_{d}\right)+e_{u^{*}}^{*}\left(d u^{*} / d t_{d}\right)=0$ and $e_{u}\left(d u / d t_{d}^{*}\right)+e_{u^{*}}^{*}\left(d u^{*} / t_{d}^{*}\right)=0$. Evaluating the slopes of these joint welfare functions at Nash equilibrium, it suffices to determine the sign of the term $e_{u^{*}}^{*}\left(d u^{*} / d t_{d}\right)$ and $e_{u}\left(d u / d t_{d}^{*}\right)$, since at Nash equilibrium $e_{u}\left(d u / d t_{d}\right)=e_{u^{*}}^{*}\left(d u^{*} / t_{d}^{*}\right)=0$. Consider, for example, the slope of the joint welfare function when Home changes its destination-based consumption tax. Evaluating the slope of the joint welfare function at Nash equilibrium gives ${ }^{23}$

\footnotetext{
${ }^{23}$ From equation 22 we have $\left.e_{u} \frac{d u}{d t_{d}}\right|_{N}=0 \Rightarrow \frac{d r}{d t_{d}}=-e_{r}^{-1}\left(e_{q_{1}}+e_{q_{2}}\right)$, and $e_{u^{*}}^{*} \frac{d u^{*}}{d t_{d}}=-e_{r^{*}}^{*} \frac{d r^{*}}{d t_{d}}$. Since by equation $21 \frac{d r}{d t_{d}}=\frac{d r^{*}}{d t_{d}}$, then at Nash equilibrium we obtain equation 26.
} 


$$
\left.e_{u^{*}}^{*} \frac{d u^{*}}{d t_{d}}\right|_{N}=e_{r^{*}}^{*} e_{r}^{-1}\left(e_{q_{1}}+e_{q_{2}}\right) .
$$

The expression in equation 26 is positive, indicating that the Nash equilibrium tax rate $t_{d}^{* N}$ is lower than the corresponding cooperative equilibrium destination-based consumption tax, i.e., $t_{d}^{N}<t_{d}^{C}$. Intuitively, when Home increases the consumption tax, it affects Foreign's welfare only through changes in pollution, i.e., the environmental externality, see equations (21) and (22). The effect on pollution depends on the level of the consumption tax. If Home's consumption tax is at the Nash equilibrium, pollution decreases affecting positively Foreign's welfare. This positive environmental externality of Home's consumption tax on Foreign's welfare is not taken into account when Home behaves Nash, and as a result the Nash equilibrium tax is lower than the cooperative one.

Proposition 3 Consider two small open economies with consumption generated cross-border pollution and where the tax revenue is used to finance public pollution abatement. The Nash equilibrium destination-based consumption taxes are lower than the corresponding cooperative taxes.

Comparing equations (9) and (26) we conclude that in the presence of cross-border consumption generated pollution, with or without public pollution abatement, Nash equilibrium destinationbased consumption taxes are inefficiently lower compared to the cooperative levels. It is only in the absence of such an externality that Nash and cooperatively set destination-based consumption taxes are equally efficient.

\subsection{Origin-based consumption taxes}

Equations (20) along with equations (18) and (19) constitute a system of five equations in $u, u^{*}, g, g^{*}$ and $r$, in terms of the policy parameters $t_{o}$ and $t_{o}^{*}$. Recall that in equation 20) $q_{1}=q_{1}^{*}=1+t_{o}$ and $q_{2}=q_{2}^{*}=1+t_{o}^{*}$. Totally differentiating equations 18$)$ and 19 we obtain the effects of changes in commodity taxes on aggregate pollution as follows:

$$
\begin{aligned}
d r & =d r^{*}=\left[-E_{q_{1}}+\left(p_{g}-t_{o}\right) E_{q_{1} q_{1}}+\left(p_{g}-t_{o}^{*}\right) E_{q_{2} q_{1}}\right] p_{g}^{-1} d t_{o} \\
& +\left[-E_{q_{2}}+\left(p_{g}-t_{o}\right) E_{q_{1} q_{2}}+\left(p_{g}-t_{o}^{*}\right) E_{q_{2} q_{2}}\right] p_{g}^{-1} d t_{o}^{*} .
\end{aligned}
$$

Totally differentiating equations 20 , changes in Home and Foreign's welfare are given as:

$$
e_{u} d u=-e_{r} d r-e_{q_{1}} d t_{o}-e_{q_{2}} d t_{o}^{*} \quad \text { and } \quad e_{u^{*}}^{*} d u^{*}=-e_{r^{*}}^{*} d r^{*}-e_{q_{1}^{*}}^{*} d t_{o}-e_{q_{2}^{*}}^{*} d t_{o}^{*}
$$

Equations (28) show that an increase in Home's origin-based consumption tax affects Foreign's welfare directly by reducing its consumption and indirectly by affecting its pollution. Using equation (27) in equations (28) we obtain analytically the welfare effects of changes in origin-based 
consumption taxes as follows:

$$
\begin{aligned}
e_{r}^{-1} p_{g} e_{u} d u & =\left[e_{r}^{-1}\left(e_{r}-p_{g}\right) e_{q_{1}}+e_{q_{1}^{*}}^{*}-\left(p_{g}-t_{o}\right) E_{q_{1} q_{1}}-\left(p_{g}-t_{o}^{*}\right) E_{q_{2} q_{1}}\right] d t_{o} \\
& +\left[e_{r}^{-1}\left(e_{r}-p_{g}\right) e_{q_{2}}+e_{q_{2}^{*}}^{*}-\left(p_{g}-t_{o}\right) E_{q_{1} q_{2}}-\left(p_{g}-t_{o}^{*}\right) E_{q_{2} q_{2}}\right] d t_{o}^{*}
\end{aligned}
$$

and,

$$
\begin{aligned}
e_{r^{*}}^{*^{-1}} p_{g} e_{u^{*}}^{*} d u^{*} & =\left[e_{r^{*}}^{*^{-1}}\left(e_{r}^{*}-p_{g}\right) e_{q_{1}^{*}}^{*}+e_{q_{1}}-\left(p_{g}-t_{o}\right) E_{q_{1} q_{1}}-\left(p_{g}-t_{o}^{*}\right) E_{q_{2} q_{1}}+\right] d t_{o} \\
& +\left[e_{r^{*}}^{*^{-1}}\left(e_{r}^{*}-p_{g}\right) e_{q_{2}^{*}}^{*}+e_{q_{2}}-\left(p_{g}-t_{o}\right) E_{q_{1} q_{2}}-\left(p_{g}-t_{o}^{*}\right) E_{q_{2} q_{2}}\right] d t_{o}^{*}
\end{aligned}
$$

\subsubsection{Efficiency of the Nash equilibrium}

Setting $e_{u}\left(d u / d t_{o}\right)=0$ and $e_{u^{*}}^{*}\left(d u^{*} / d t_{o}^{*}\right)=0$, in equations (29) and (30) and solving them simultaneously, the Nash equilibrium origin-based consumption taxes, with cross-border pollution and public pollution abatement are given as follows:

$$
\begin{gathered}
t_{o}^{N}=p_{g}+\bar{E}_{q_{1} q_{1}}\left[e_{r}^{-1} e_{q_{1}}\left(p_{g}-e_{r}\right)-e_{q_{1}^{*}}^{*}-E_{q_{2} q_{2}}^{-1} E_{q_{2} q_{1}}\left(e_{r^{*}}^{-^{-1}} e_{q_{2}^{*}}^{*}\left(p_{g}-e_{r^{*}}^{*}\right)-e_{q_{2}}\right)\right], \text { and } \\
t_{o}^{*^{N}}=p_{g}+\bar{E}_{q_{2} q_{2}}\left[e_{r^{*}}^{*^{-1}} e_{q_{2}^{*}}^{*}\left(p_{g}-e_{r^{*}}^{*}\right)-e_{q_{2}}-E_{q_{1} q_{1}}^{-1} E_{q_{1} q_{2}}\left(e_{r}^{-1} e_{q_{1}}\left(p_{g}-e_{r}\right)-e_{q_{1}^{*}}^{*}\right)\right] .
\end{gathered}
$$

recall that $\bar{E}_{q_{1} q_{1}}=E_{q_{1} q_{1}}-E_{q_{1} q_{2}} E_{q_{2} q_{2}}^{-1} E_{q_{2} q_{1}}<0$ and similarly $\bar{E}_{q_{2} q_{2}}<0$.

We evaluate whether in the presence of cross-border pollution and public pollution abatement, the Nash origin-based consumption taxes are equally efficient as the corresponding cooperative taxes. The cooperative equilibrium origin-based consumption taxes are determined by simultaneously setting $e_{u}\left(d u / d t_{o}\right)+e_{u^{*}}^{*}\left(d u^{*} / d t_{o}\right)=0$ and $e_{u}\left(d u / d t_{o}^{*}\right)+e_{u^{*}}^{*}\left(d u^{*} / t_{o}^{*}\right)=0$. Evaluating the slope of the joint welfare function at Nash equilibrium, it suffices to determine the sign of the term $e_{u}^{*}\left(d u^{*} / d t_{o}\right)$ since at Nash equilibrium $e_{u}\left(d u / d t_{o}\right)=0$. Doing so, after some algebraic manipulation we obtain 24

$$
\left.e_{u^{*}}^{*} \frac{d u^{*}}{d t_{o}}\right|_{N}=\underbrace{-e_{q_{1}}^{*}}_{\text {private consumption externality }} \underbrace{-e_{r^{*}}^{*}\left(d r^{*} / d t_{o}\right)}_{\text {environmental externality }}=e_{q_{1}}\left(\frac{e_{r^{*}}^{*}}{e_{r}}-\frac{e_{q_{1}^{*}}^{*}}{e_{q_{1}}}\right) .
$$

Equation (32) shows that the Nash origin-based consumption tax can be equal, higher or lower than the cooperative equilibrium tax. Intuitively, when Home increases its origin-based consumption tax, first it affects Foreign's welfare negatively due to the reduction of the consumption of good

\footnotetext{
${ }^{24}$ From equation $\left[29,\left.e_{r}^{-1} p_{g} e_{u} \frac{d u}{d t_{o}}\right|_{N}=0 \Longrightarrow-\left(p_{g}-t_{o}\right) E_{q_{1} q_{1}}-\left(p_{g}-t_{o}^{*}\right) E_{q_{2} q_{1}}=-e_{r}^{-1}\left(e_{r}-p_{g}\right) e_{q_{1}}-e_{q_{1}^{*}}^{*}\right.$. Substituting this expression into the expression for $e_{r^{*}}^{*-1} p_{g} e_{u}^{*} \frac{d u^{*}}{d t_{o}}$, after some algebra, we arrive to the result in equation 32 .
} 
1. This is the private consumption externality, and is captured by the term $-e_{q_{1}}^{*}$. Second, it exerts an ambiguous impact on Foreign's welfare through its impact on the country's level of pollution. This is the environmental externality, here captured by the term $-e_{r}^{*}\left(d r^{*} / d t_{o}\right)$. At Nash equilibrium this externality is positive since $\left(d r^{*} / d t_{0}\right)=-e_{q_{1}} / e_{r}<025$ Therefore, at Nash equilibrium the two externalities are of opposite sign, and thus the total effect on welfare is ambiguous. Elaborating further, equation (32), shows that the overall impact of Home's higher consumption tax on Foreign's welfare is $e_{q_{1}}\left(\frac{e_{r^{*}}^{*}}{e_{r}}-\frac{e_{q_{1}^{*}}^{*}}{e_{q_{1}}}\right)$. The latter expression allows us to identify clear conditions under which the decentralized setting of the origin-based consumption taxes is equally efficient as their cooperative setting. Specifically, if $\frac{e_{r_{r}^{*}}^{*}}{e_{r}}=\frac{e_{q_{1}^{*}}^{*}}{e_{q_{1}}}$, then the negative private consumption externality is exactly equal to the positive environmental externality, and thus, the Nash and cooperative equilibrium origin-based consumption taxes are equally efficient. Based on the above we state the following Proposition.

Proposition 4 Consider two small open economies with consumption generated cross-border pollution and where consumption tax revenues are used to finance the provision of public pollution abatement. The decentralized (Nash) equilibrium and the cooperative equilibrium origin-based consumption taxes coincide if, $\frac{e_{r^{*}}^{*}}{e_{r}}=\frac{e_{q_{1}^{*}}^{*}}{e_{q_{1}}}$.

This result resembles the celebrated result by Ogawa and Wildasin (2009), who in a completely different context conclude that the non-cooperative policy setting can coincide with the cooperative one, thus, leading to an efficient outcome. In their framework, cross-border pollution arises from capital, which is considered perfectly mobile across different jurisdictions, and governments use capital taxation to control pollution. Here, we obtain the efficient outcome of the non-cooperative policy setting in a context where emissions arise from consumption, and governments use the revenue from origin-based consumption taxes to finance the provision of public pollution abatement.

The result of the above Proposition holds not only when countries are symmetric but also when they are not, provided that individuals in each country have the same income and preferences, or alternatively they have identical and homothetic preferences.

Corollary 1 Consider two open economies with consumption generated cross-border pollution where consumption tax revenue is used to finance the provision of public pollution abatement. The Nash equilibrium and the cooperative equilibrium origin-based consumption taxes coincide if the individuals in the two countries have identical incomes and preferences, or have identical and homothetic preferences.

The literature on the efficiency of the origin and destination principle usually employs models where the two countries are symmetric or identical, see for example, among others, Moriconi and Sato (2009), Haufler and Pflüger (2007). The present analysis assumes a representative individual

\footnotetext{
${ }^{25}$ From equation $\sqrt{27}$ and using that at the Nash equilibrium $\left.e_{r}^{-1} p_{g} e_{u} \frac{d u}{d t_{o}}\right|_{N}=0$ and $\left.e_{r^{*}}^{*} p_{g} e_{u}^{*} \frac{d u^{*}}{d t_{o}^{*}}\right|_{N}=0$, we get that at $\operatorname{Nash}\left(d r^{*} / d t_{o}\right)=\left(-e_{q_{1}} / e_{r}\right)<0$.
} 
in each country, but it can also apply to the case of countries with unequal population. In the latter case, what is required is that individuals in each country have identical incomes and preferences or have identical and homothetic preferences.

\section{Concluding Remarks}

A key issue in international commodity taxation is whether taxes should be levied in the jurisdictions of destination or origin. Based on the fundamental characteristics and differences of the two tax principles, OECD (2014), p. 24, reports ".... the destination principle is the international norm and is sanctioned by the OECD International VAT/GST Guidelines and by the World Trade Organisation rules ...". Without disputing the proclaimed advantages or disadvantages that international organizations and policy makers attribute to one tax system over the other, this paper shows that, under certain conditions, in the presence of consumption generated pollution the Nash equilibrium origin-based consumption taxes are efficient.

We build a two country perfectly competitive model with consumption generated cross-border pollution, where consumption tax revenues are either lump-sum distributed or used to finance public pollution abatement. Within this framework, when tax revenue is used to finance public pollution abatement, the Nash and cooperative equilibrium taxes are equally efficient under the restricted origin principle. This result holds not only in the context of symmetric countries, but also in the case of non-symmetric countries with unequal population, provided that households have identical incomes and preferences or have identical and homothetic preferences. However, the Nash equilibrium commodity taxes under the destination principle are lower than their corresponding cooperative equilibrium levels.

In addition, the paper also shows that in the absence of public pollution abatement, in which case the tax revenues are lump-sum distributed, the Nash equilibrium taxes under both principles are inefficient. The Nash equilibrium taxes under the destination principle are lower than the corresponding cooperative taxes. The Nash and cooperative equilibrium origin-based consumption taxes are higher than the corresponding levels of the non-pollution case. Moreover, in the absence of pollution, the origin-based Nash equilibrium taxes are always higher than the cooperative ones, while in the presence of pollution the Nash equilibrium taxes may be lower than their corresponding cooperative equilibrium levels.

\section{References}

[1] Beghin, J., D. Holst and D. van der Mensbrugghe, 1997, Trade and pollution linkages: piecemeal reform and optimal intervention, Canadian Journal of Economics 30, 442-455.

[2] Behrens, K., Hamilton, J.H., Ottaviano G.I.P. and J-F. Thisse, 2009, Commodity tax competition and industry location under the destination and the origin principle, Regional Science and Urban Economics 39, 422-33. 
[3] Chao C-C., Laffargue, J-P. and P. Sgro, 2012, Tariff and environmental policies with product standards, Canadian Journal of Economics 45, 978-995.

[4] Chao C-C. and E.S.H. Yu, 2015, Environmental impacts of tariff and tax reforms under origin and destination principles, Pacific Economic Review 20, 310-322.

[5] Cremer, H. and F. Gahvari, 2006, Which border taxes? Origin and destination regimes with fiscal competition in output and emission taxes, Journal of Public Economics 90, 2121-2142.

[6] EPA, 2014, Sources of greenhouse emissions. Retrieved October 2016: http://www.epa.gov/ghgemissions/sources-greenhouse-gas-emissions

[7] Gulati, S. and D. Roy, 2008, National treatment and the optimal regulation of environmental externalities, Canadian Journal of Economics 41, 1445-71.

[8] Haibara, T., and H. Ohta, 2011, A new proposal for ecological tax reforms, GSICS Working Papers Series no. 24, Kobe University.

[9] Haufler, A., 1994, Unilateral tax reform under the restricted origin principle, European Journal of Political Economy 10, 511-527.

[10] Haufler, A. and M. Pflüger, 2007, International Oligopoly and the taxation of commerce with revenue-constrained governments, Economica 74, 451-473.

[11] Haufler, A., Schjelderup, G. and F. Stähler, 2005, Barriers to trade and imperfect competition: the choice of commodity tax base, International Tax Public Finance, 12, 281-300.

[12] Hu, B., and R. McKitrick 2015, Decomposing the Environmental Effects of Trade Liberalization: The Case of Consumption-Generated Pollution, Environmental and Resource Economics, forthcoming.

[13] Kanbur, R. and M. Keen, 1993, Jeux sans frontiers: tax competition and tax coordination when countries differ in size, American Economic Review 63, 877-892.

[14] Keen , M., and C. Kotsogiannis, 2014, Coordinating climate and trade policies: Pareto efficiency and the role of border tax adjustments, Journal of International Economics 94, 119-128.

[15] Keen , M., and S. Lahiri, 1998, The comparison between destination and origin principles under imperfect competition, Journal of International Economics 45, 323-50.

[16] Keen, M., and D. Wildasin, 2004, Pareto-efficient international taxation, American Economic Review 94, 259-75.

[17] Lai, Y-B. and C-H. Hu, 2008, Trade agreements, domestic environmental regulation, and transboundary polluttion, Resource and Energy Economics 30, 209-228. 
[18] Linster, M. and F. Zegel, 2007, Pollution abatement and control expenditure in OECD countries, Discussion Paper.ENV/EPOC/SE (March 2007) 1.Paris:OECD.

[19] Lockwood, B., 2001, Tax competition and tax co-ordination under destination and origin principles: a synthesis, Journal of Public Economics 81, 279-319.

[20] Mintz, J. and H. Tulkens, 1986, Commodity tax competition between member states of a federation: equilibrium and efficiency, Journal of Public Economics, 29, 133-72.

[21] Moriconi, S. and Y. Sato, 2006, Commodity taxation in the presence of unemployment, CORE Discussion Papers 2006/69.

[22] Moriconi, S. and Y. Sato, 2009, International Commodity Taxation in the presence of unemployment, Journal of Public Economics 93, 939-949.

[23] Ng, Y. K., 2008, Environmentally responsible happy nation index: Towards an internationally acceptable national success indicator, Social Indicators Research 85, 425-446.

[24] OECD, 2014, Consumption Tax Trends 2014: VAT/GST and Excise Rates,Trends and Policy Issues, OECD Publishing, Paris. Retrieved October 2016: http://dx.doi.org/10.1787/ctt-2014en

[25] Ogawa, H., and D. Wildasin, 2009, Think locally, act locally: Spillovers, spillbacks and efficient decentralized policy making, American Economic Review 99, 1206-17.

[26] Ong, Q. and E. Quah, 2014, Welfare perception on public expenditure on environmental and non-environmental goods, Theoretical Economics Letters 4, 457-464.

[27] Rehdanz, K. and D. Maddison, 2005, Climate and happiness, Ecological Economics 52, 111125.

[28] Welsch, H., 2006, Environment and happiness: Valuation of air pollution using life satisfaction data, Ecological Economics 58, 801-813. 